\title{
SOME CLINICAL ASPECTS OF HUMAN CYTOGENETICS
}

\author{
L. S. Penrose, F.R.S., D.Sc., M.A., M.D. \\ Galton Professor of Eugenics, University College, London, W.C.I
}

\begin{abstract}
ExPECTATIONs of discoveries, relating chromosome aberrations in tumour cells to the type of growth, benign or malignant, have not often been justified. Cultures from most tumours have normal karyotypes and in leukæmias, for example, the abnormalities found, except for the famous Philadelphia deletion in the chronic myeloid type, are not consistent or characteristic. Moreover, a mongol with leukæmia remains an ordinary trisomic mongol.

However, a direct relationship between somatic disease and chromosomal aberration is sometimes demonstrable by investigating other types of problems which arise in clinical medicine. Four examples have been chosen.
\end{abstract}

\section{A Distinguished Patient}

In 19I4, after three girls, at last a boy was born in a sibship. The ambitious father named the boy after the physician and surgeon whom he admired most, hoping that the boy would grow up to be a famous doctor. In the course of a search for chromatin-positive males, which I had instituted in $195^{8}$, a man was discovered who had, independently, the clinical features characteristic both of Klinefelter's syndrome and of mongolism. After considerable delay in obtaining relative's consent and hospital facilities for tissue biopsies, the help of Dr. C. E. Ford was enlisted to direct cytological investigations. The result was a precise karyotype analysis which showed trisomy of both an autosome and a sex chromosome, making 48 in all, and leaving no possible doubt about the relationship of chromosomes to clinical type. Forming the subject of the first paper on human chromosomes to be published in the Lancet this man, who should have been a famous doctor, at the age of 45 , has become a famous patient.

\section{An Extraordinary Chromosome}

Nearly all patients who have an anomaly, such as an extra chromosome, in their somatic cells, show fairly obvious characteristic physical abnormality. So that I thought it likely to be a waste of time, when I was asked to arrange for cytological examination of a normal-looking girl of 13 , with

A paper read to the Harveian Society of London on December 20, 196r. mental retardation, kyphosis and epilepsy of recent origin. It seemed that psychiatric and neurological tests had failed to make any diagnosis and that cytology was the last resort.

Surprisingly, both skin and leucocyte cultures showed the presence of an extra chromosome, $\vec{\omega}$ superficially resembling that triplicated in mon $\Rightarrow$ golism. On detailed investigation, however, Dro J. R. Ellis showed this aberrant object to be a chromosome of a type never previously seen ino man; it has satellite bodies at both ends. The parents and a normal sister had normal karyotypese and the origin and significance of this aberrationoo in the patient's cells is a challenge to geneticists.

\section{Human Triploids}

For the next example the chief credit must go to a patient who made the brilliant suggestign $\overrightarrow{0}$ that it might be possible to obtain useful inform tion by culturing fotal remnants from her missed abortion. The material, obtained by curettage though macerated and amorphous, contained a recognisable yolk sac. This and also another smallo explant were successfully cultured and showed市 triploid cells with 69 chromosomes. The sex complement was XXY indicating that the fœtus might have arisen from a male sperm with 23 ? chromosomes fertilising an unreduced ovum with 46.

Not long afterwards a second similar culture was obtained from an early spontaneous miscarriage. These two cases seem to be the first instances where spontaneous abortions have been: proved to have been cytologically abnormal. The only previously described human triploidy응 occurred in a proportion of somatic cells in a defective Swedish boy. In all these cases the $\frac{D}{0}$ parents tested have shown normal diploid karyotypes.

\section{Significant Culture from an Umbilical Cord}

In 1957, I was consulted by a husband and wife, aged 27 and 29 respectively, who were worried and puzzled because two out of their three children $\mathbb{\varnothing}$ were mongols. I could do little more than make $\stackrel{?}{+}$ my customary examinations and give a guarded $\frac{T}{0}$ prognosis, noting especially that previous observa- $\frac{O}{\mathbb{D}}$ tions had shown the existence of a group of 

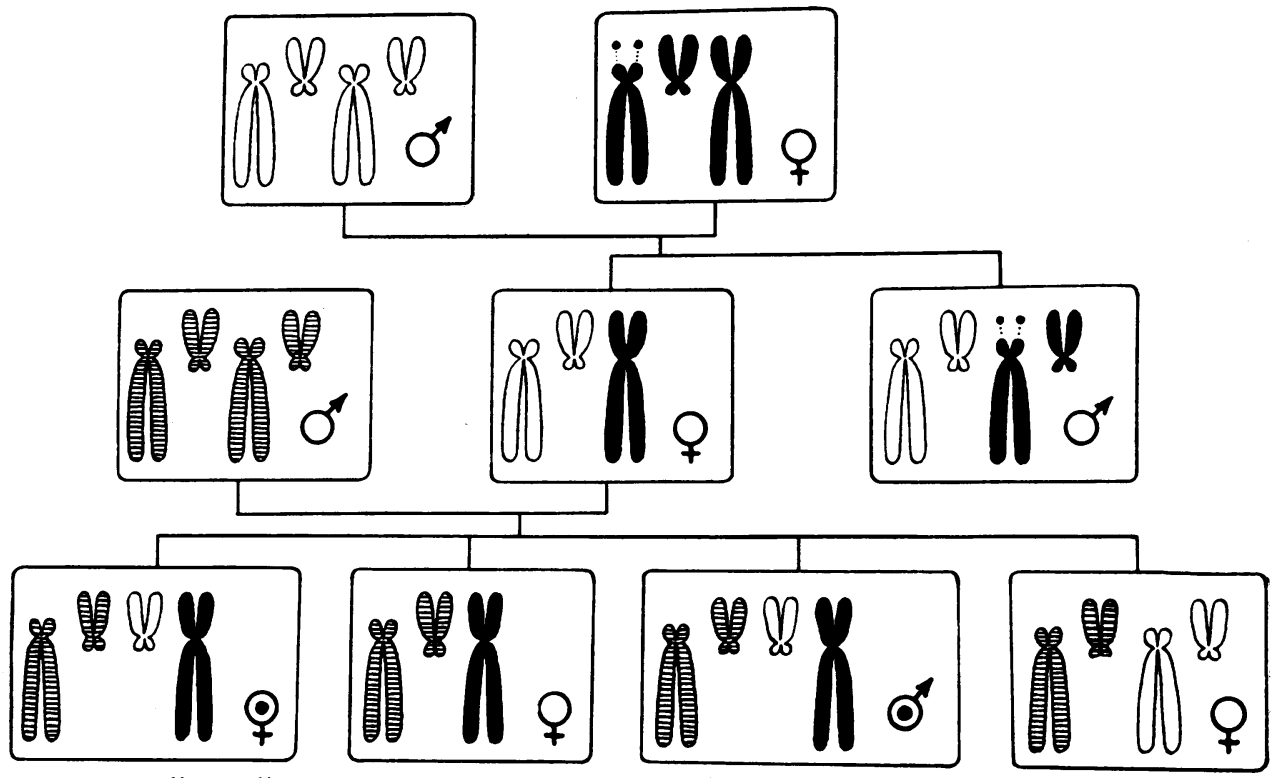

FIG. I.-Pedigree diagram showing transmission of chromosomes Nos. 15 and 21 in three generations. Three normal females and two mongols carry a fused $15: 21$ chromosome. In each frame the two chromosomes on the left are assumed to be derived from the father and the others from the mother. In the mongols the greater part of chromosome No. 21 is represented three times.

relatively young mothers, predisposed to have mongol children.

By the end of 1960 I was in touch with the family again. By that time Ford and Polani had found a translocated mongol, with 46 chromosomes, born to a young mother; both parents of that case turned out to have normal karyotypes. In the family under consideration, a full analysis was made by skin culture technique. The mother carried a fused chromosome, nearly equal to a normal No. 21 and a No. 15 added together, and had a total count of 45 ; so also did her mother and her normal daughter. The mongol daughter and mongol son each had only 46 chromosomes, like the case previously described. The father and the maternal grandfather had normal karyotypes with 46 chromosomes. The mother's brother, who had a hare lip and cleft palate (very well corrected in childhood), was also cytologically normal though he had one rather strongly satellited large acrocentric as did his mother.
In spite of grave warnings from their friendso and their medical advisers, this mother became pregnant again. A period of extreme anxietyo ensued and it was arranged that a culture of tissue from the umbilical cord of the infant would be obtained so that a diagnosis could be made as early as possible and appropriate information given to the parents. The infant was born at home, earlier than expected, but the doctor in charge managed to preserve a piece of cord in normal saline. The specimen was eventually cultured successfully by Mrs. Delhanty. The karyotype proved to be unequivocally that of a normal female with 46 chromosomes and the baby was clinically perfectly healthy. It is interesting to note that, in this family, leaving aside the question of recombination, the pathways of inheritance of actual homologous chromosome pairs Nos. I 5 and 21 can be traced through three generations (see Fig. I).

\section{REFERENCES}

Baikie, A. G., Court Brown, W. M., Buckton, K. E. Harnden, D. G., Jacobs, P. A., and Tough, I. M. (i96o): A Possible Specific Chromosome Abnormality in Human Chronic Myeloid Leukæmia, Nature (Lond.), 188, 1165.

Ellis, J. R., Marshall, R., and Penrose, L. S. (196r): An Extra Chromosome with Satellite on the Long Arm in a Female Patient (paper read to the 137 th Meeting of the Genetical Society, November 196r).

Ford, C. E., Jones, K. W., Miller, O. J., Mittwoch, U., Penrose, L. S., Ridler, M., and Shapiro, A. (i959): The Chromosomes in a Patient showing both Mongolism and the Klinefelter Syndrome, Lancet, $\mathrm{i}, 709$.

Penrose, L. S., Ellis, J. R., and Delhanty, J. D. A. (r 960): Chromosomal Translocations in Mongolism and in Normal Relatives, Ibid., ii, 409 .

—, and Delhanty, J. D. A. (r96r): Triploid Cell Cultures from a Macerated Fœtus, Ibid., i, 126r. 